\title{
Composição bromatológica do capim-Marandu sob efeito de irrigação e adubação nitrogenada
}

\section{Bromatologic composition the Marandu grass under effect of different irrigation and nitrogen fertilization}

\author{
João Avelar Magalhães ${ }^{1 *}$; Maria Socorro de Souza Carneiro²; \\ Alex Carvalho Andrade 3 ; Elzânia Sales Pereira ${ }^{4}$; Braz Henrique Nunes Rodrigues ${ }^{5}$; \\ Newton de Lucena Costa ${ }^{6}$; Fabíola Helena dos Santos Fogaça $a^{7}$ \\ Karina Neoob de Carvalho Castro ${ }^{8}$; Claudio Ramalho Townsend ${ }^{9}$
}

\begin{abstract}
Resumo
Foram avaliados os efeitos de diferentes lâminas de irrigação e doses de nitrogênio sobre a composição química da Brachiaria brizantha cv. Marandu. O estudo foi conduzido na Embrapa Meio-Norte, localizada no município de Parnaíba, Piauí. Os tratamentos consistiram em duas lâminas de irrigação (reposição de $50 \%$ e $80 \%$ da Evaporação do Tanque Classe "A" - ECA) e quatro doses de nitrogênio

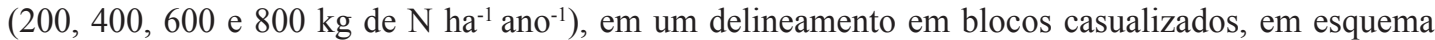
fatorial $2 \times 4$, com três repetições. A lâmina de irrigação de $50 \%$ de evaporação do tanque classe A promove aumento nos teores de matéria seca e reduz os teores de fibra em detergente neutro (FDN) e de fibra em detergente ácido (FDA), porém não influencia o conteúdo de proteína bruta, ao mesmo tempo em que o nitrogênio confere aumento nos teores de proteína bruta e propicia diminuição nos teores de FDN e FDA das folhas, melhorando o valor nutritivo do capim-Marandu.
\end{abstract}

Palavras-chave: FDA, FDN, matéria seca, proteína bruta

\begin{abstract}
The effects of different irrigation and nitrogen $(\mathrm{N})$ on the chemical composition of Brachiaria brizantha var. Marandu were evaluated. The study was conducted at Embrapa Mid-North, located in the city of Parnaíba, Piauí. The treatments consisted of two irrigation levels (replacement of $50 \%$ and $80 \%$ of
\end{abstract}

\footnotetext{
${ }^{1}$ Médico Veterinário, Dr., Pesquisador da Empresa Brasileira de Pesquisa Agropecuária, EMBRAPA, Centro de Pesquisa Agropecuária do Meio-Norte, Parnaíba, PI. E-mail: joao.magalhaes@embrapa.br

2 Eng ${ }^{\mathrm{a}} \mathrm{Agr}^{\mathrm{a}}$, Prof ${ }^{\mathrm{a}}$ Dr $^{\mathrm{a}}$, Universidade Federal do Ceará, UFC. Fortaleza, CE. E-mail. msocorro@ufc.br

3 Zootecnista, Prof. Dr., Universidade Estadual do Piauí, UESPI. Parnaíba, PI. E-mail: acandrade4@hotmail.com

${ }^{4}$ Zootecnista, Prof ${ }^{a}$ Dr $^{\text {a }}$, UFC. Fortaleza, CE. E-mail: elzania@hotmail.com

${ }^{5}$ Eng $^{\circ}$ Agrícola, Dr., Pesquisador, EMBRAPA, Centro de Pesquisa Agropecuária do Meio-Norte. Parnaíba, PI. E-mail: braz. rodrigues@embrapa.br

${ }^{6} \mathrm{Eng}^{\mathrm{O}} \mathrm{Agr}^{\mathrm{O}}$, Dr., Pesquisador, EMBRAPA, Centro de Pesquisa Agroflorestal de Roraima. Boa Vista, RR. E-mail: newton.lucenacosta@embrapa.br

7 Zootecnista, Dr ${ }^{\mathrm{a}}$, Pesquisadora, EMBRAPA, Centro de Pesquisa Agropecuária do Meio-Norte, Parnaíba, PI. E-mail: fabiola. fogaca@embrapa.br

${ }^{8}$ Médica Veterinária, $\mathrm{Dr}^{\mathrm{a}}$, Pesquisadora, EMBRAPA, Centro de Pesquisa Agropecuária do Meio-Norte. Parnaíba, PI. E-mail: karina.castro@embrapa.br

9 Zootecnista, Dr., Pesquisador, EMBRAPA, Centro de Pesquisa Agropecuária de Clima Temperado, Pelotas, RS. E-mail: claudio. townsend@embrapa.br

* Autor para correspondência
} 
Class A pan evaporation - ECA) and four levels of nitrogen (200, 400, 600 and $800 \mathrm{~kg} \mathrm{~N} \mathrm{ha}^{-1}$ ano $\left.^{-1}\right)$, in a block randomized in a $2 \times 4$ factorial design with three replications. The irrigation $50 \%$ of class A pan evaporation promotes an increase in dry matter and reduces the levels of neutral detergent insoluble fiber (NDF) and acid detergent insoluble fiber (ADF), however, does not influence the content of crude protein, while the nitrogen confers increased protein levels and provides gross decrease in NDF and ADF of leaves, improving the nutritional value of the Marandu grass.

Key words: ADF, crude protein, dry matter, NDF

\section{Introdução}

No Brasil, e principalmente na região Nordeste, durante o período chuvoso a produção de forragem é satisfatória, entretanto, nos períodos secos ou de escassez de chuvas, a produção de forragem decresce a níveis críticos, refletindo negativamente no desempenho produtivo dos animais, devido à baixa ingestão de forragem.

A falta de água no solo afeta a fotossíntese, respiração, divisão celular, germinação, absorção e translocação de nutrientes, prejudicando o desenvolvimento da planta, e consequentemente, a produção de forragem. Todavia, há evidências que déficits hídricos suaves tendem a melhorar o valor nutritivo da planta, devido ao atraso na maturidade e no desenvolvimento do colmo, com a manutenção de uma boa relação folha/colmo (MISLEVY; EVERETT, 1981; WILSON, 1982; HALIM et al., 1989).

Uma das alternativas para reduzir a estacionalidade da produção de forragem, causada pela deficiência hídrica, é a irrigação, principalmente em regiões onde outros fatores como temperatura e luminosidade permanecem próxima de um padrão adequado para produção de plantas tropicais.

Nos trópicos grande parte das pastagens é cultivada em solos de baixa fertilidade natural, com condições que limitam o crescimento vegetal, reduzindo o seu potencial de produção, sendo necessária a utilização de adubos químicos. Com objetivo de aumentar a produtividade das gramíneas forrageiras por área e por animal, cresce no país a utilização de sistemas intensivos de produção de leite em pastagem. Todavia, numa dieta onde a fonte principal de nutriente é a pastagem deve-se levar em consideração o valor nutritivo da forragem produzida, que na maioria das gramíneas tropicais é baixo, devido à genética, condições de solo e de manejo.

$\mathrm{Na}$ opinião de Euclides (1995), a adubação nitrogenada reveste-se de vital importância para o setor pecuário, pois além de promover o aumento da produção de fitomassa das gramíneas, estimula o crescimento de tecidos novos, com altos teores de proteína bruta, baixos de fibra em detergente neutro (FDN) e lignina.

No Brasil, a maioria das pesquisas com pastagens foi conduzida em condições de sequeiro, sendo escassos os experimentos com pastagens irrigadas, sobretudo, quando são utilizadas pastagens irrigadas e adubadas com nitrogênio. Além disso, o valor nutritivo das plantas forrageiras é, sem dúvida, um dos mais importantes fatores relacionados com a produção animal a ser obtida em condições de pastejo. Por isso, é de grande importância o conhecimento prévio da sua composição químicobromatológica, principalmente os teores de matéria seca (MS), proteína bruta (PB), fibra em detergente neutro (FDN) e fibra em detergente ácido (FDA).

Por essas razões, o objetivo deste trabalho foi avaliar os efeitos de diferentes lâminas de irrigação e da adubação nitrogenada sobre os teores de matéria seca, de proteína bruta, de fibra em detergente neutro e em ácido da Brachiaria brizantha cv. Marandu nas condições edafoclimáticas da região do Baixo Parnaíba piauiense. 


\section{Material e Métodos}

$\mathrm{O}$ trabalho foi conduzido na área experimental da Embrapa Meio-Norte, em Parnaíba, Piauí, durante o período de agosto a dezembro de 2007. O clima é do tipo AW', segundo classificação de Köppen, com ventos moderados e umidade relativa do ar de moderada a alta. A precipitação anual média é de $1.300 \mathrm{~mm}$ e o período chuvoso se concentra nos meses de janeiro a junho. O solo da área experimental foi classificado como Latossolo Amarelo distrófico, textura média, fase caatinga litorânea de relevo plano e suave ondulado (MELO et al., 2004) que no início do experimento apresentou as seguintes características químicas $\mathrm{MO}=15,28 \mathrm{~g} \mathrm{~kg}^{-1} ; \mathrm{pH}$ $\left(\mathrm{H}_{2} \mathrm{O}\right)=5,48 ; \mathrm{P}=13,45 \mathrm{mg} \mathrm{dm}^{-3} ; \mathrm{K}=0,04 \mathrm{cmol}_{\mathrm{c}}$ $\mathrm{dm}^{-3} ; \mathrm{Ca}=1,51 \mathrm{cmol}_{\mathrm{c}} \mathrm{dm}^{-3} ; \mathrm{Mg}=0,44 \mathrm{cmol}_{\mathrm{c}} \mathrm{dm}^{-3}$; $\mathrm{Na}=0,16 \mathrm{cmol}_{\mathrm{c}} \mathrm{dm}^{-3} ; \mathrm{Al}=0,01 \mathrm{cmol}_{\mathrm{c}} \mathrm{dm}^{-3} ; \mathrm{H}+\mathrm{Al}$ $=1,25 \mathrm{cmol}_{\mathrm{c}} \mathrm{dm}^{-3} ; \mathrm{S}=2,14 \mathrm{cmol}_{\mathrm{c}} \mathrm{dm}^{-3} ; \mathrm{CTC}=3,40$ $\mathrm{cmol}_{\mathrm{c}} \mathrm{dm}^{-3} ; \mathrm{V}=63,04 \% ; \mathrm{m}=0,69 \%$.

As parcelas experimentais foram implantadas no início do período chuvoso de 2005, aplicando-se em todas as parcelas a dosagem equivalente a 50 $\mathrm{kg} \mathrm{ha}^{-1}$ de $\mathrm{P}_{2} \mathrm{O}_{5}$, na forma de superfosfato triplo e $40 \mathrm{~kg} \mathrm{ha}^{-1} \mathrm{de} \mathrm{K}_{2} \mathrm{O}$, na forma de cloreto de potássio em fundação e $45 \mathrm{~kg} \mathrm{ha}^{-1}$ de nitrogênio na forma de ureia, parceladas em duas aplicações, uma no plantio e outra 30 dias após. Os tratamentos consistiram em duas lâminas de irrigação (reposição de $50 \%$ e 80\% da Evaporação do Tanque Classe "A" - ECA) e quatro doses de nitrogênio $(200,400,600$ e 800 $\mathrm{kg} \mathrm{ha}^{-1} \mathrm{ano}^{-1}$ ), em um delineamento em blocos casualizados, em esquema fatorial $2 \times 4$, com três repetições. As parcelas experimentais mediam $3 \mathrm{~m}$ x $8 \mathrm{~m}$, com $2 \mathrm{~m}$ x $7 \mathrm{~m}$ de área útil, sendo realizados um corte de uniformização (agosto) e quatro cortes para coleta de dados a cada 30 dias, a $20 \mathrm{~cm}$ do solo.

Logo após o corte de uniformização procedeuse a primeira adubação referente a cada tratamento. A adubação nitrogenada, sob forma de uréia, foi aplicada a lanço (imediatamente após cada corte) e de acordo com as quantidades estabelecidas nos tratamentos $(16,7 ; 33,3 ; 50,0$ e $66,7 \mathrm{~kg}$ de $\mathrm{N}$ mês ${ }^{-1}$ ). Durante o período experimental foram aplicados 66,$8 ; 133,2 ; 200,00$ e 266,8 $\mathrm{kg}^{\mathrm{de}} \mathrm{N} \mathrm{ha}^{-1}$, respectivamente. Com turno de irrigação de três dias, foi utilizado um sistema de aspersão convencional fixo, de baixa pressão e vazão. O espaçamento entre linhas laterais e entre aspersores foi de 12 $\mathrm{m} \times 12 \mathrm{~m}$. Visando manter um rigoroso controle do tempo de irrigação e facilidade operacional, o ensaio possuía um conjunto moto-bomba próprio. Os valores das lâminas totais de irrigação aplicadas nos tratamentos dos níveis de irrigação (50\% e $80 \%$ da evaporação do Tanque Classe "A"), durante o período experimental, foram de $471,99 \mathrm{~mm}$ e $755,18 \mathrm{~mm}$, respectivamente.

Após cada corte das gramíneas, foram obtidas amostras que, depois de separadas em folha (lâmina foliar) e colmo (colmo+bainha) e pesadas em balança eletrônica, foram submetidas à présecagem em estufa com circulação forçada de ar, a $65{ }^{\circ} \mathrm{C}$ por 72 horas. No Laboratório de Nutrição Animal da Universidade Federal do Ceará (UFC), foram determinados os teores de matéria seca (MS), de proteína bruta (PB), pelo método de Kjeldahl, fibra em detergente neutro (FDN) e fibra em detergente ácido (FDA), de acordo com a metodologia preconizada por Silva e Queiroz (2002). A digestão para obtenção da FDN e FDA foi realizada em aparelho de digestão de fibra (modelo Tecnal TE-149, similar ao Ankon). As amostras foram colocadas em saquinhos de tecido de TNT $100 \mathrm{~mm}$, sendo que em cada um foi depositado 0,5 $\mathrm{g}$ de massa do capim-Marandu pré-seca moída em peneira de $1 \mathrm{~mm}$.

Os resultados obtidos foram submetidos à análise de variância para observação da existência ou não de interação adubação x lâminas de irrigação, e as médias foram comparadas pelo teste de Tukey, ao nível de $5 \%$ de probabilidade. As equações de regressão foram obtidas isolando-se cada lâmina de irrigação em função das doses de nitrogênio. Os dados amostrados foram analisados utilizando-se o pacote estatístico Assistat (SILVA; AZEVEDO, 2006). 


\section{Resultados e Discussão}

A irrigação promoveu efeitos significativos $(\mathrm{P}<0,05)$ nos teores de matéria seca $(\mathrm{MS})$ da folha e do colmo (Tabela 1). Nas folhas o maior teor de MS correspondeu a menor lâmina aplicada. Assim sendo, neste trabalho, as plantas que receberam o tratamento $50 \%$ de ECA dispunham de menores quantidades de água para ser absorvida do solo, e, consequentemente, apresentaram menores teores de água nas células, resultando em maiores teores de MS. Alencar et al. (2009) também registraram redução nos teores de matéria seca nas folhas com o aumento das lâminas de irrigação, em seis gramíneas forrageiras, dentre elas os capins Marandu e Xaráes, que são cultivares da espécie Brachiaria brizantha.

Tabela 1. Teores de matéria seca (MS) em folhas e colmos do capim Brachiaria brizantha cv. Marandu, sob efeito de irrigação e adubação nitrogenada (N). Parnaíba, Piauí.

\begin{tabular}{|c|c|c|c|c|c|c|c|c|}
\hline \multirow{3}{*}{ Lâminas de irrigação } & \multicolumn{4}{|c|}{ Doses de $\mathrm{N}\left(\mathrm{kg} \mathrm{ha}^{-1} \mathrm{ano}^{-1}\right)$} & \multirow{3}{*}{ Médias** } & \multirow{3}{*}{ Equação de regressão } & \multirow{3}{*}{$\mathrm{R}^{2}$} & \multirow{3}{*}{$\mathrm{CV}(\%)$} \\
\hline & 200 & 400 & 600 & 800 & & & & \\
\hline & \multicolumn{4}{|c|}{ Folhas (\% de MS) } & & & & \\
\hline $50 \%$ de $\mathrm{ECA}^{1}$ & 26,43 & 25,91 & 26,21 & 24,94 & $25,87 \mathrm{~A}$ & Sem ajuste & - & 6,85 \\
\hline $80 \%$ de $\mathrm{ECA}^{1}$ & 26,52 & 24,93 & 22,67 & 22,05 & $23,87 \mathrm{~B}$ & $\hat{\mathrm{y}}=27,6183-0,089883 * * \mathrm{~N}$ & 0,94 & 1,75 \\
\hline \multirow[t]{2}{*}{ CV $(\%)$} & 5,92 & & & & & & & \\
\hline & \multicolumn{4}{|c|}{ Colmos (\% de MS) } & & & & \\
\hline $50 \%$ de $\mathrm{ECA}^{1}$ & 22,06 & 21,18 & 20,88 & 20,53 & $21,16 \mathrm{~B}$ & Sem ajuste & - & 4,12 \\
\hline $80 \%$ de $\mathrm{ECA}^{1}$ & 24,35 & 26,99 & 26,00 & 24,29 & $25,41 \mathrm{~A}$ & Sem ajuste & - & 9,42 \\
\hline CV (\%) & 7,23 & & & & & & & \\
\hline
\end{tabular}

Na coluna, médias seguidas por letras distintas diferem entre si, pelo teste de Tukey a $1 \%$ **.

Significativo pelo teste $\mathrm{F}$ a $1 \%$ ** de probabilidade.

$\mathrm{ECA}=$ Evaporação do Tanque Classe "A".

Fonte: Elaboração dos autores.

Diferentemente das folhas, os teores de MS observados nos colmos foram proporcionais às lâminas aplicadas (Tabela 1). A lâmina de $80 \%$ aumentou $(\mathrm{P}<0,05)$ em $20 \%$ os teores de MS nos colmos em relação a lamina de 50\% ECA. Possivelmente a maior lâmina impulsionou o crescimento da planta, necessitando de modificações estruturais nos tecidos e no metabolismo. Tendências semelhantes foram observadas por Vanzela et al. (2006) em capim-Tanzânia irrigado com zero, 50\%, $100 \%$ e $150 \%$ de ECA, e adubado com $0,25,50$ e $100 \mathrm{~kg}$ de $\mathrm{N} \mathrm{ha}^{-1}$ corte $^{-1}$.

$\mathrm{Na}$ maior lâmina de irrigação aplicada foi observado efeito linear $(\hat{y}=27,6183-0,089883 N$;
$\left.\mathrm{R}^{2}=0,94\right)$ da adubação nitrogenada sobre os teores de MS nas folhas do capim-Marandu, corroborando com os resultados de Aguiar, Vasquez e Silva (2000). No entanto, os teores de matéria seca observados neste experimento são inferiores aos descritos por Ferreira et al. (2002), que obtiveram 27,49\% de MS na folha, e 30,16\% de MS no colmo do capim-Marandu, cultivado em Latossolo VermelhoEscuro, adubado com nitrogênio e cortado aos 42 dias de idade.

A análise de variância não detectou interação $(\mathrm{P}>0,05)$ entre lâminas de água e doses de nitrogênio sobre os teores de proteína bruta (PB) do capimMarandu (Tabela 2). 
Tabela 2. Teores de proteína bruta (PB) em folhas e colmos do capim Brachiaria brizantha cv. Marandu, sob efeito de irrigação e adubação nitrogenada (N). Parnaíba, Piauí.

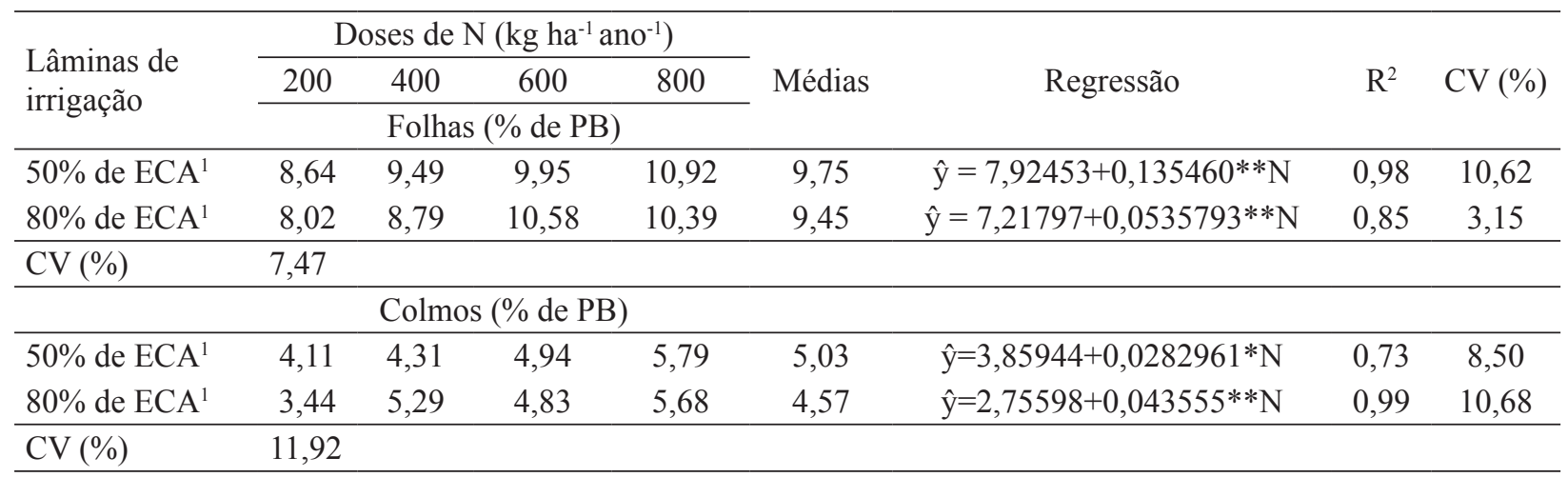

Significativo pelo teste $\mathrm{F}$ a $1 \% * *$ e $5 \% *$ de probabilidade.

$\mathrm{ECA}=$ Evaporação do Tanque Classe ${ }^{\mathrm{a}}$

Fonte: Elaboração dos autores.

As lâminas de irrigação testadas não provocaram efeitos estatísticos $(\mathrm{P}>0,05)$ sobre os teores $\mathrm{PB}$. Este resultado não era esperado, pois, geralmente ocorrem diferenças significativas nas concentrações de proteína bruta, visto que maiores lâminas de água implicam em maiores produções de matéria seca e/ ou em antecipação da maturidade das gramíneas, ocasionando diluição dos teores de nitrogênio, resultando em menores teores de proteína bruta. Santos, Silva e Chaves (2008) também não encontraram diferenças significativas nos teores de proteína bruta dos capins Marandu e Tifton irrigado em relação ao não irrigado.

No município de Campos dos Goytacazes, em experimento conduzido por cinco meses, Palieraqui et al. (2006) não observaram influência da irrigação sobre os teores de proteína bruta das folhas do capim-Mombaça e capim-elefante, ratificando os dados observados por Rodrigues, Magalhães e Lopes (2005), que relataram não haver respostas expressivas dos teores de proteína bruta do capimTifton 85 às diferentes lâminas de água $(20 \%, 60 \%$ e 100\% de ECA) aplicadas através da irrigação por gotejamento.

Dentro de cada lâmina, a análise de regressão detectou linearidade dos efeitos dos níveis de nitrogênio sobre os teores de proteína bruta da folha e do colmo. Respostas semelhantes foram obtidas por Costa et al. (2009) em variedades Brachiaria brizantha, adubado com quatro doses de nitrogênio (0,100, 150 e $200 \mathrm{mg}$ de $\left.\mathrm{N} \mathrm{dm}^{3}\right)$ em três cortes, realizados a cada 30 dias em casa de vegetação. $\mathrm{Na}$ Venezuela, numa região de precipitação pluvial média de $1.256 \mathrm{~mm}$, Pietrosemoli, Gerardo e Villalobos (1996) avaliaram os efeitos da aplicação de 0,200 e $400 \mathrm{~kg}$ de $\mathrm{N} \mathrm{ha}^{-1}$ sobre os teores de proteína bruta do capim Brachiaria brizantha, cujas médias obtidas foram, respectivamente, $10,41 \% ; 14,47 \%$ e $16,78 \%$. Tendências semelhantes foram reportadas por Whitney (1974), Márquez et al. (2007), Ayub et al. (2009) e Ullah, Anwar e Rana (2010). De acordo com Havlin et al. (2005), quando o nitrogênio é fornecido adequadamente e em condições favoráveis para o crescimento das plantas, proporciona aumento na produção de MS e no teor de proteína.

Em geral, os teores de proteína observados neste trabalho estão próximos aos descritos por Euclides (1995), quando compararam o efeito do período chuvoso x período seco sobre os teores de PB do capim-Marandu, cujas médias de PB foram, 11,1\% (folha), 6,0\% (colmo), 8,1\% (folha) e 3,8\% (colmo), respectivamente, para o período chuvoso e período seco. Ademais, neste experimento, apenas os teores 
de PB observados nos colmos não atenderia o valor mínimo de 7\%. Visto que, de acordo com Minson (1984), valores de PB inferiores a 7\% podem causar redução na atividade dos microorganismos do rúmen, o que consequentemente causa decréscimo nas taxas de fermentação da digestão e da passagem dos alimentos no trato digestivo, resultando em redução do consumo voluntário, limitando assim a produção máxima dos animais.

As lâminas de irrigação influenciaram $(\mathrm{P}<0,05)$ os teores de FDN do capim-Marandu (Tabela 3), cujas médias verificadas foram, para folhas, $62,39 \%$ (50\% de ECA) e $64,41 \%$ ( $80 \%$ de ECA); e para colmos, $72,13 \%$ (50\% de ECA) e 75,39\% (80\% de ECA). Com crescimento restrito em função do menor aporte de água, observou-se menores teores FDN nas lâminas e colmos mantidos sob $50 \%$ da ECA. As maiores lâminas de irrigação aceleraram o crescimento das plantas e, consequentemente sua maturidade fisiológica, que não é interessante para ruminantes, pois reduz o consumo afetando o desempenho animal. Nas condições edafoclimáticas de Viçosa, Minas Gerais, Andrade et al. (2002) evidenciaram que os teores médios de FDN em capim-elefante cv. Napier irrigado $(70,6 \%)$ foram significativamente superiores ao capim não irrigado $(66,6 \%)$.

Tabela 3. Teores de fibra em detergente neutro (FDN) em folhas e colmos do capim Brachiaria brizantha cv. Marandu, sob efeito de irrigação e adubação nitrogenada (N). Parnaíba, Piauí.

\begin{tabular}{|c|c|c|c|c|c|c|c|c|}
\hline \multirow{3}{*}{$\begin{array}{l}\text { Lâminas de } \\
\text { irrigação }\end{array}$} & \multicolumn{4}{|c|}{ Doses de N $\left(\mathrm{kg} \mathrm{ha}^{-1} \mathrm{ano}^{-1}\right)$} & \multirow{3}{*}{ Médias** } & \multirow{3}{*}{ Equação de regressão } & \multirow{3}{*}{$\mathrm{R}^{2}$} & \multirow{3}{*}{ CV $(\%)$} \\
\hline & 200 & 400 & 600 & 800 & & & & \\
\hline & \multicolumn{4}{|c|}{ Folhas (\% de FDN) } & & & & \\
\hline $50 \%$ de $\mathrm{ECA}^{1}$ & 63,87 & 63,27 & 61,87 & 60,53 & $62,39 \mathrm{~B}$ & $\hat{\mathrm{y}}=65,249342-0,068626^{*} \mathrm{~N}$ & 0,97 & 2,71 \\
\hline $80 \%$ de $\mathrm{ECA}^{1}$ & 65,68 & 64,68 & 64,46 & 62,84 & $64,41 \mathrm{~A}$ & Sem ajuste & - & 2,16 \\
\hline \multirow[t]{2}{*}{ CV (\%) } & 2,36 & & & & & & & \\
\hline & \multicolumn{4}{|c|}{ Colmos ( $\%$ de FDN) } & & & & \\
\hline $50 \%$ de $\mathrm{ECA}^{1}$ & 71,64 & 72,82 & 71,63 & 72,96 & $72,13 \mathrm{~B}$ & Sem ajuste & - & 6,44 \\
\hline $80 \%$ de $\mathrm{ECA}^{1}$ & 73,35 & 74,49 & 75,79 & 77,93 & $75,39 \mathrm{~A}$ & $\hat{\mathrm{y}}=71,628811+0,0904 * \mathrm{~N}$ & 0,97 & 2,22 \\
\hline CV (\%) & 4,83 & & & & & & & \\
\hline
\end{tabular}

Na coluna, médias seguidas por letras distintas diferem entre si, pelo teste de Tukey a $1 \%$ **.

Significativo pelo teste $\mathrm{F}$ a $5 \%$ * de probabilidade.

$\mathrm{ECA}=$ Evaporação do Tanque Classe ${ }^{\mathrm{a}}$

Fonte: Elaboração dos autores.

Dentro da lâmina de irrigação de $50 \%$ da ECA, os níveis crescentes de nitrogênio promoveram efeitos lineares negativos sobre os teores de FDN das folhas, descrito pela equação: $\hat{y}=65,249342$ - $0,068626 * \mathrm{~N} ; \mathrm{R}^{2}=0,97$. Esta melhoria ocorrida nos teores de FDN pode ser explicada pelo fato do nitrogênio estimular a formação de novos tecidos, que geralmente tem menores teores de FDN e maiores teores de proteína bruta. Tendências semelhantes foram reportadas por Cecato et al. (2004) que observaram decréscimos nos teores de
FDN do capim-Marandu, adubado com 200, 400 e $600 \mathrm{~kg}$ de N/ha. Johnson et al. (2001) revelaram que os teores de FDN dos capins $C$. dactylon, $C$. nlemfuensis e Paspalum notatum decresceram linearmente em função do aumento da adubação nitrogenada $\left(0,39,78,118,157 \mathrm{~kg}\right.$ de $\left(\mathrm{kg} \mathrm{ha}^{-1}\right.$ corte $\left.^{-1}\right)$, fato também observado por Taute et al. (2012) e Quaresma et al. (2011).

Referindo-se aos colmos do capim-Marandu, os teores de FDN responderam de forma linear às doses de nitrogênio $(\hat{y}=71,628811+0,0904 * N$; 
$\left.\mathrm{R}^{2}=0,97\right)$, fato observado na lâmina de $80 \%$ da ECA. Provavelmente, o nitrogênio promoveu desenvolvimento foliáceo, e consequentemente, alongamento do caule para sustentação da parte aérea, causando antecipação da maturidade. Para Hoffman et al. (2007), à medida que as plantas crescem, desenvolvem o tecido xilemático para transporte de água, acumulam celulose e outros carboidratos complexos para sustentação e estes tecidos se fixam através do processo da lignificação. O efeito combinado promove mudanças fisiológicas na parede celular, causando aumento dos teores de FDN.

Os teores de FDA da folha e colmo do capimMarandu foram influenciados $(\mathrm{P}<0,05)$ pelas lâminas de irrigação (Tabela 4). Os maiores valores foram observados quando se utilizou as maiores lâminas de irrigação, cujas médias do FDA das folhas foram $30,14 \%$ e $32,34 \%$, e dos colmos $36,10 \%$ e $38,08 \%$, respectivamente, para $50 \%$ e $80 \%$ da ECA. Respostas semelhantes foram descritas por Melo et al. (2007) quando repuseram 25, 50, 75 e 100\% da água consumida no processo evapotranspirativo do milheto (Pennisetum glaucum). Estes resultados são inferiores aos obtidos por Santos, Silva e Chaves (2008) em capim-Marandu irrigado (40,2\%) e não irrigado (42,9\%), ficando bem próximos aos 34\% de FDA observados por Costa et al. (2007) na planta inteira do capim B. brizantha cv. MG-5, entre 20 e 30 dias de idade, em experimento conduzido em um Argissolo Vermelho-Amarelo eutrófico em casa de vegetação. A FDA é um indicativo da digestibilidade e valor energético da forragem, sendo que quanto menor a FDA, maior será o valor energético da planta.

Tabela 4. Teores de fibra em detergente ácido (FDA) em folhas e colmos do capim Brachiaria brizantha cv. Marandu, sob efeito de irrigação e adubação nitrogenada (N). Parnaíba, Piauí.

\begin{tabular}{|c|c|c|c|c|c|c|c|c|}
\hline \multirow{3}{*}{ Lâminas de irrigação } & \multicolumn{4}{|c|}{ Doses de $\mathrm{N}\left(\mathrm{kg} \mathrm{ha}^{-1} \mathrm{ano}^{-1}\right)$} & \multirow{3}{*}{ Médias** } & \multirow{3}{*}{ Equação de regressão } & \multirow{3}{*}{$\mathrm{R}^{2}$} & \multirow{3}{*}{$\mathrm{CV}(\%)$} \\
\hline & 200 & 400 & 600 & 800 & & & & \\
\hline & \multicolumn{4}{|c|}{ Folhas ( $\%$ de FDA) } & & & & \\
\hline $50 \%$ de $\mathrm{ECA}^{1}$ & 31,23 & 30,46 & 29,65 & 29,23 & $30,14 \mathrm{~B}$ & $\hat{y}=31,840941-0,040781 * N$ & 0,98 & 2,80 \\
\hline $80 \%$ de $\mathrm{ECA}^{1}$ & 32,84 & 32,68 & 32,54 & 31,43 & $32,34 \mathrm{~A}$ & Sem ajuste & - & 2,54 \\
\hline \multirow[t]{2}{*}{ CV $(\%)$} & 3,10 & & & & & & & \\
\hline & \multicolumn{4}{|c|}{ Colmos (\% de FDA) } & & & & \\
\hline $50 \%$ de $\mathrm{ECA}^{1}$ & 36,45 & 36,36 & 35,77 & 35,81 & $36,10 \mathrm{~B}$ & Sem ajuste & - & 2,59 \\
\hline $80 \%$ de $\mathrm{ECA}^{1}$ & 37,67 & 38,44 & 38,30 & 37,92 & $38,08 \mathrm{~A}$ & Sem ajuste & - & 2,48 \\
\hline CV (\%) & 3,01 & & & & & & & \\
\hline
\end{tabular}

Na coluna, médias seguidas por letras distintas diferem entre si, pelo teste de Tukey a 1\%**. Significativo pelo teste $\mathrm{F}$ a $5 \%$ * de probabilidade.

$\mathrm{ECA}=$ Evaporação do Tanque Classe ${ }^{\mathrm{a}}$.

Fonte: Elaboração dos autores.

Os teores de fibra em detergente ácido (FDA) têm relação com os teores de lignina dos alimentos, que determinam a digestibilidade da fibra, pois quanto menor o teor de FDA, menor será o teor de lignina e, consequentemente, melhor a digestibilidade do alimento. Observou-se que os menores teores de FDA foram obtidos no tratamento de menor lâmina de água. De acordo com Wilson (1982) a escassez de água para a planta causa atraso na maturidade, no crescimento e desenvolvimento do caule, diminuindo o processo de lignificação.

Dentro da lâmina de irrigação de 50\% de ECA, a análise de regressão apresentou efeito significativo 
$(\mathrm{P}<0,05)$ do nitrogênio sobre os teores de FDA das folhas $\left(\hat{\mathrm{y}}=31,840941-0,040781 * \mathrm{~N} ; \mathrm{R}^{2}=0\right.$, 98). Costa et al. (2009) também notaram reduções lineares nos teores de FDA dos capim-Marandu $(\hat{\mathrm{y}}$ $\left.=37,73-0,0307 \mathrm{~N} ; \mathrm{R}^{2}=0,96.\right)$, capim-MG-4 $(\hat{\mathrm{y}}=$ $\left.37,923-0,0221 \mathrm{~N} ; \mathrm{R}^{2}=0,94\right)$ e capim-Xaraés $(\hat{\mathrm{y}}=$ $\left.37,1590-0,0336 \mathrm{~N} ; \mathrm{R}^{2}=0,97\right)$, indicando melhora no valor nutritivo das gramíneas testadas. Já autores como Cecato et al. (2001) e Quaresma et al. (2011) não encontraram influências do nitrogênio sobre os teores de FDA do capim Cynodon sp.

\section{Conclusões}

A lâmina de irrigação de $50 \%$ de evaporação do tanque classe "A" promove aumento nos teores de matéria seca e reduz os teores de FDA e FDN, porém não influencia o conteúdo de proteína bruta, ao mesmo tempo em que o nitrogênio confere aumento nos teores de proteína bruta e propicia diminuição nos teores de FDN e FDA das folhas, melhorando o valor nutritivo do capim-Marandu.

\section{Referências}

AGUIAR, R. S.; VASQUEZ, H. M.; SILVA, J. F. C. Produção e composição químico-bromatológico do capim-furachão (Panicum repens L.) sob adubação e diferentes idades de corte. Revista Brasileira de. Zootecnia, Viçosa, MG, v. 29, n. 2, p. 325-333, 2000.

ALENCAR, C. A. B.; COSER, A. C.; MARTINS, C. E.; OLIVEIRA, R. A. de; CECON, P. R.; LEAL, B. G.; FIGUEIREDO, J. L. A.; CUNHA, F. F. da. Produção doses de nitrogênio e estações do ano afetando a composição bromatológica e digestibilidade de capins cultivados sob pastejo. Revista Ceres, Viçosa, MG, MG, v. 56, n. 5 , p. $640-647,2009$.

ANDRADE, A. C.; FONSECA, D. M.; LOPES, R. S.; NASCIMENTO JÚNIOR, D.; GOMIDE, J. A.; CECON, P. R.; QUEIROZ, D. S.; PEREIRA, D. H.; CARDOSO, R. C. Disponibilidade de matéria seca e composição química do capim-elefante cv. Napier sob adubação e irrigação. In: REUNIÃO ANUAL DA SOCIEDADE BRASILEIRA DE ZOOTECNIA, 39., 2002, Recife. Anais... Recife: SBZ, 2002. CD-ROM.
AYUB, M.; NADEEM, M. A.; TAHIR, M.; IBRAHIM, M.; ASLAM, M. N. Effect of nitrogen application and harvesting intervals on forage yield and quality of pearl millet (Pennisetum americanum). Pakistan Journal of Life and Social Science, Faisalabad, v. 7, n. 2, p. $185-$ 189, 2009.

CECATO, U.; PEREIRA, L. A. F.; JOBIM, C. C.; MARTINS, E. N.; BRANCO, A. F.; GALBEIRO, S.; MACHADO, A. O. Influência da adubação nitrogenada e fosfatada sobre a composição químico-bromatológica do capim Marandu. Acta Scientiarum. Animal Sciences, Maringá, v. 26, n. 3, p. 409-416, 2004.

CECATO, U.; SANTOS, G. T.; MACHADO, F. A.; GOMES, L. H.; DAMACENO, J. C.; JOBIM, C. C.; RIBAS, N. P.; MIRA, R. T.; CANO, C. C. P. Avaliação de cultivares do gênero Cynodon com e sem nitrogênio. Acta Scientiarum. Animal Sciences, Maringá, v. 23, n. 4, p. 781-788, 2001.

COSTA, K. A. P.; OLIVEIRA, I. P. de; FAQUIN, V.; NEVES, B. P. das; RODRIGES, C.; SAMPAIO, F. de M. T. Intervalo de corte na produção de massa seca e composição químico-bromatológica da Brachiaria brizantha cv. MG-5. Acta Scientiarum. Animal Sciences, Maringá, v. 31, n. 4, p. 1197-1202, 2007.

COSTA, K. A. P.; OLIVEIRA, I. P. de; FAQUIN, V.; SILVA, G. P.; SEVERIANO, E. C. Produção de massa seca e nutrição de cultivares de Brachiaria brizantha sob doses de nitrogênio. Ciência e Agrotecnologia, Lavras, v. 33, n. 6, p. 1578-1585, 2009.

EUCLIDES, V. P. B. Valor alimentício de espécies forrageiras do gênero Panicum. SIMPÓSIO SOBRE MANEJO DA PASTAGEM, 12., 1995, Piracicaba. Anais... Piracicaba: FEALQ, 1995. p. 245-273.

FERREIRA, J. J. C.; RABELO, L. S.; BORGES, A. L. C. C.; GONÇALVES, L. C.; JAYME, C. G.; PIRES, D. A. A.; JAYME, D. G.; BORGES, I.; RODRIGUEZ, N. M.; SALIBA, E. O. S. Relação folha/haste e seus teores de matéria seca da Brachiaria brizantha cv. Marandu em oito épocas de corte. In: SEMANA DA INICIAÇÃO CIENTÍFICA, 10., 2002, Belo Horizonte. Anais... Belo Horizonte: UFMG, 2002. v. 1, p. 25. CD-ROM.

HALIM, R. A.; BUXTON, D. R.; HATTENDORF, M. J.; CARLOSN, R. E. Water stress effects on alfafa forage quality after adjustment for maturity differences. Agronomy Journal, Madison, v. 81, n. 2, p. 189-194, 1989.

HAVLIN, J. L.; BEATON, J. D.; TISDALE, S. L.; NELSON, W. L. Soil fertility and fertilizers: an introduction to nutrient management. 7. ed. New Jersey: Pearson 2005. 515 p. 
HOFFMAN, P. C.; LUNDBERG, K. M.; BAUMAN, L. M.; SHAVER, R. D.; CONTRERAS-GOVEA, F. E. El efecto de la madurez en la digestibilidad del FDN (fibra detergente neutro). Focus on Forage, Madison, v. 5, n. 15, p. 1-2, 2007.

JOHNSON, C. B.; REILING, B. A.; MISLEVY, P.; HALL, M. B. Effects of nitrogen fertilization and harvest date on yield, digestibility, fiber, and protein fractions of tropical grasses. Journal of Animal Science, Savoy, v. 79, n. 9, p. 2439-2448, 2001.

MÁRQUEZ, F.; SÁNCHEZ, J.; URBANO, D.; DÁVILA, C. Evaluación de la frecuencia de corte y tipos de fertilización sobre tres genotipos de pasto elefante (Pennisetum purpureum): 1. Rendimiento y contenido de proteína. Zootecnia Tropical, Maracay, v. 25, n. 4, p. 253-259, 2007.

MELO, D.; SOUSA, A.; SOUTO, J.; PEREIRA, R. Avaliação do milheto (Pennisetum glaucum (1.) b. r.) sob diferentes níveis de água no solo. In: CONGRESSO DE PESQUISA E INOVAÇÃO DA REDE NORTE NORDESTE DE EDUCAÇÃO TECNOLÓGICA, 2., 2007, João Pessoa. Anais... João Pessoa: CEFET, 2007. CD-ROM.

MELO, F. B.; CAVALCANTE, A. C.; ANDRADE JÚNIOR, A. S.; BASTOS, E. A. Levantamento detalhado dos solos da área da Embrapa Meio-Norte/UEP de Parnaiba. Teresina: Embrapa Meio-Norte, 2004. 26 p. (Documentos, 89).

MINSON, D. J. Effects of chemical and physical composition of herbaje eaten upon intake. In: HACKER, J. B. (Ed.). Nutritional limits to animal production from pasture. Farnham Royal: CAB, 1984. p. 167-182.

MISLEVY, P.; EVERETT, P. H. Subtropical grass species response to different irrigation and harvest regimes. Agronomy Journal, Madison, v. 73, n. 4, p. 601-604, 1981.

PALIERAQUI, J. G. B.; FONTES, C. A. de A.; RIBEIRO, E. G.; CÓSER, A. C.; MARTINS, C. E. M.; FERNANDES, A. M. Influência da irrigação sobre a disponibilidade, a composição química, a digestibilidade e o consumo dos capins Mombaça e napier. Revista Brasileira de. Zootecnia, Viçosa, MG, v. 35, n. 6, p. 2381-2387, 2006.

PIETROSEMOLI, S.; GERARDO, L.; VILLALOBOS, N. Respuesta del pasto Bracharia brizantha a la fertilización nitrogenada. Revista de la Facultad de Agronomía, Luz, v. 13, n. 5, p. 551-560, 1996.
QUARESMA, J. P. de S.; ALMEIDA, R. G. de; ABREU, J. G. de; CABRAL, L. da S.; OLIVEIRA, M. de A.; CARVALHO, D. M. G. de. Produção e composição bromatológica do capim-tifton 85 (Cynodon spp.) submetido a doses de nitrogênio. Acta Scientiarum. Animal Sciences, Maringá, v. 33, n. 2, p. 145-150, 2011.

RODRIGUES, B. H. N.; MAGALHÃES, J. A.; LOPES, E. A. Irrigação e adubação nitrogenada em três gramíneas forrageiras no Meio-Norte do Brasil. Revista Ciência Agronômica, Fortaleza, v. 36, n. 3, p. 274-278, 2005.

SANTOS, N. L.; SILVA, M. W. R.; CHAVES, M. A. Efeito da irrigação suplementar sobre a produção dos capins Tifton 85, Tanzânia e Marandu no período de verão no Sudoeste Baiano. Ciência Animal Brasileira, Goiânia, v. 9, n. 4, p. 911-922, 2008.

SILVA, D. J.; QUEIROZ, A. C. Análises de alimentos: métodos químicos e biológicos. 3. ed. Viçosa: Imprensa Universitária. UFV, 2002. 235 p.

SILVA, F. de A. S. E.; AZEVEDO, C. A. V. de. A new version of the assistat-statistical assistance software. In: WORLD CONGRESS ON COMPUTERS IN AGRICULTURE, 4., 2006, Orlando. Anais... Orlando: ASAE, 2006. p. 393-396.

TAUTE, A.; NIEKERK, W. W.; RETHMAN, N. F. G.; COETZE, R. J. An evaluation of nitrogen fertilized Panicum maximum cv. Gatton at different stages of maturity during autumn: 1 . Dry matter yield and certain qualitative parameters. South African Journal of Animal Science, Pretoria, v. 32, n. 3, p. 208-216, 2012.

ULLAH, M. A.; ANWAR, M.; RANA, A. S. Effect of nitrogen fertilization and harvesting intervals on the yield and forage quality of elephant grass (Pennisetum purpureum) under mesic climate of Pothowar plateau. Pakistan Journal of Agricultural Sciences, Faisalabad, v. 47, n. 3, p. 231-234, 2010.

VANZELA, L. S.; HERNANDEZ, F. B. T.; GARGANTINI, P. E.; LIMA, R. C. Qualidade de forragem de capim-Mombaça sob irrigação na região oeste do estado de São Paulo. In: CONGRESSO NACIONAL DE IRRIGAÇÃO E DRENAGEM, 16., Goiânia, 2006. Anais... Goiânia: ABID, 2006. CD-ROM.

WHITNEY, A. S. Growth of kikuyu grass (Pennisetum clandestinum) under clipping. Effects of nitrogen fertilization, cutting interval, and season on yields and forage characteristics. Agronomy Journal, Madison, v. 66, n. 2, p. 281-287, 1974.

WILSON, J. R. Evironmental and nutritional factors affecting herbage quality. In: HACKER, J. B. (Ed.). Nutritional limits to animal production from pastures. Farnham: CAB, 1982. p. 111-131. 
